\title{
Simultaneous lack of catalase and beta-toxin in Staphylococcus aureus leads to increased intracellular survival in macrophages and epithelial cells and to attenuated virulence in murine and ovine models
}

\author{
Susana Martínez-Pulgarín,† Gustavo Domínguez-Bernal, José A. Orden \\ and Ricardo de la Fuente
}

Correspondence

Ricardo de la Fuente

rifuente@vet.ucm.es

Received 28 October 2008

Revised 20 February 2009

Accepted 26 February 2009
Departamento de Sanidad Animal, Facultad de Veterinaria, Universidad Complutense de Madridł, Avda. Puerta de Hierro s/n, 28040 Madrid, Spain

\begin{abstract}
Staphylococcus aureus produces a variety of virulence factors that allow it to cause a wide range of infections in humans and animals. In the latter, $S$. aureus is a leading cause of intramammary infections. The contribution of catalase (KatA), an enzyme implicated in oxidative stress resistance, and beta-toxin ( $\mathrm{Hlb}$ ), a haemolysin, to the pathogenesis of $S$. aureus is poorly characterized. To investigate the role of these enzymes as potential virulence factors in $S$. aureus, we examined the intracellular survival of $\Delta k a t A, \Delta h / b$ and $\Delta k a t A \Delta h l b$ mutants in murine macrophages (J774A.1) and bovine mammary epithelial cells (MAC-T), and their virulence in different murine and ovine models. Catalase was not required for the survival of $S$. aureus within either J774A.1 or MAC-T cells. However, it was necessary for the intracellular proliferation of the bacterium after invasion of MAC-T cells. In addition, catalase was not needed for the full virulence of $S$. aureus in mice.

Deletion of the $h / b$ gene had no effect on the intracellular survival of $S$. aureus in J774A.1 cells but did cause a slight increase in survival in MAC-T cells. Furthermore, like catalase, beta-toxin was not required for complete virulence of $S$. aureus in murine models. Unexpectedly, the $\Delta k a t A \Delta h / b$ mutant showed a notably increased persistence in both cell lines, and was significantly less virulent for mice than were the wild-type strain and single mutants. Most interestingly, it was also markedly attenuated in intramammary and subcutaneous infections in ewes and lambs.
\end{abstract}

\section{INTRODUCTION}

Staphylococcus aureus is a ubiquitous micro-organism that is responsible for a wide range of both acute and chronic infections in humans and animals. In animals, S. aureus is frequently associated with intramammary infections in lactating females, which cause substantial economic losses in dairy production (Sutra \& Poutrel, 1994). The ability of S. aureus to cause disease has been attributed to its ability to produce a variety of surface-expressed (protein A, fibrinogen-, fibronectin- and collagen-binding proteins) and secreted (haemolysins, enterotoxins, proteases, lipase and coagulases) virulence factors that allow it to colonize

tPresent address: Departamento de Biotecnología, Instituto Nacional de Investigación y Tecnología Agraria y Alimentaria (INIA), Crta. de La Coruña km. 7.5, 28040 Madrid, Spain.

$\ddagger$ The University Complutense of Madrid (Spain) has filed a patent on the $\Delta k a t A \Delta h l b$ strain as a vaccine against ruminant mastitis.

Abbreviations: CAMP, Christie-Atkins-Munch-Petersen; $\mathrm{Cl}$, competitive index; SCCs, somatic cell counts. and multiply in tissues (Dinges et al., 2000; Kerro Dego et al., 2002). Furthermore, although $S$. aureus is not traditionally considered to be an intracellular pathogen, numerous studies have clearly demonstrated that $S$. aureus can internalize and survive in a wide variety of mammalian cells (Bayles et al., 1998; Menzies \& Kourteva, 1998; Wesson et al., 1998), including phagocytic cells (Brouillette et al., 2003; Hébert et al., 2000).

Catalase (KatA) is an enzyme involved in oxidative stress resistance, and converts hydrogen peroxide generated during cellular metabolism to water and molecular oxygen. As a result, catalase has been proposed to be a potential virulence factor in many bacterial pathogens, because its activity might protect them from the reactive oxygen species (ROS) generated by eukaryotic cells. Thus, this enzyme has been demonstrated to be an essential factor for the intracellular survival of bacteria such as Mycobacterium tuberculosis (Manca et al., 1999), Campylobacter jejuni (Day et al., 2000) and Helicobacter pylori (Basu et al., 2004). In S. aureus, the role of catalase in virulence remains unclear; 
while some researchers have observed a correlation between virulence and catalase activity (Kanafani \& Martin, 1985; Mandell, 1975), others have not found any evidence of this (Cosgrove et al., 2007; Horsburgh et al., 2001).

Beta-toxin (Hlb) is one of the haemolysins produced by $S$. aureus, and works as a sphingomyelinase C, degrading sphingomyelin in the outer layer of eukaryotic cell membranes. This toxin is also known for producing 'hot-cold' haemolysis on sheep blood agar plates. It is characterized by incomplete haemolysis at $37{ }^{\circ} \mathrm{C}$, followed by complete haemolysis during incubation at $4{ }^{\circ} \mathrm{C}$. It has been proposed that the cytolytic activity of beta-toxin results from induction of changes in the physical properties of the cell membrane, and induction of apoptosis by generation of ceramide, a potent secondary messenger that arises from sphingomyelin hydrolysis (Bayles et al., 1998; Hannun \& Obeid, 1995). A high percentage (75-97\%) of $S$. aureus strains isolated from bovine mastitis produce beta-toxin, whereas only $10-15 \%$ of human isolates express this factor (Aarestrup et al., 1999; Larsen et al., 2002). To date, the role of beta-toxin in S. aureus pathogenesis is little known. However, some studies have suggested that this toxin is important in intramammary infection. Purified toxin has been shown to cause moderate inflammatory changes in mouse and rabbit mammary glands (Calvinho et al., 1993; Ward et al., 1979) and to be cytotoxic for bovine mammary epithelial cells (Cifrian et al., 1996). In addition, non-beta-toxin-producing mutants have been found to be less virulent than wild-type strains in a mouse model of intramammary infection (Bramley et al., 1989) but not in non-mammary models (Nilsson et al., 1999; O'Callaghan et al., 1997).

The aim of this work was to investigate the role of catalase and beta-toxin as potential virulence factors in $S$. aureus. We constructed $\Delta k a t A, \Delta h l b$ and $\Delta k a t A \Delta h l b$ mutants and compared their ability to survive in macrophages and epithelial cells, as well as their virulence in different murine and ovine models, with those of the wild-type strain.

\section{METHODS}

Bacterial strains, plasmids and growth conditions. The strains and plasmids used in this study are listed in Table 1. S. aureus strains were routinely grown at $37{ }^{\circ} \mathrm{C}$ in brain heart infusion (BHI) broth with shaking or on BHI agar plates. For protoplast regeneration, DM3 medium was used (Götz et al., 1981). When appropriate, erythromycin $\left(5 \mu \mathrm{g} \mathrm{ml}^{-1}\right)$ was incorporated. Columbia agar with $5 \%$ sheep blood was utilized in order to observe haemolytic activity. Escherichia coli strains were cultured in Luria-Bertani medium, with ampicillin $\left(50 \mu \mathrm{g} \mathrm{ml}^{-1}\right)$ and erythromycin $\left(300 \mu \mathrm{g} \mathrm{ml}^{-1}\right)$ added as required. The S. aureus strain 2386 was isolated from a cow with acute mastitis. This strain was chosen for our studies due to its potentially high intramammary pathogenicity, which was later confirmed in experimental infections in ewes. The 2386 strain belongs to spa type t543 and sequence type ST479.

DNA manipulations and transformation. Chromosomal DNA from $S$. aureus was extracted using a GFX Genomic Blood DNA
Purification kit (Amersham Pharmacia Biotech) according to the manufacturer's protocol, except for a first lysis step with lysostaphin (50-100 $\mu \mathrm{g} \mathrm{ml}^{-1}$, Sigma) at $37^{\circ} \mathrm{C}$ for $30 \mathrm{~min}$. Plasmid DNA isolation was performed using a Plasmid Purification kit (Qiagen), adding preincubation with lysostaphin for $S$. aureus, as described above. Plasmids were transformed into $S$. aureus by protoplast transformation (Götz et al., 1981). Transformation of E. coli was performed by standard procedures (Ausubel et al., 1992). DNA fragments were isolated with the Qiaquick PCR Purification kit (Qiagen) and the Qiaquick Gel Extraction kit (Qiagen). Restriction enzymes were supplied by Amersham Pharmacia Biotech.

PCRs were carried out with AmpliTaq Gold polymerase (Applied Biosystems), as recommended by the manufacturer. Oligonucleotide primers used in this study (Table 1 ) were designed using the $S$. aureus COL genome sequence (TIGR Microbial Database) and purchased from Isogen Bioscence.

Construction of $\Delta k a t A, \Delta h / b$ and $\Delta k a t A \Delta h / b$ mutants. S. aureus strain 2386, a clinical isolate from bovine mastitis, was used for construction of the mutants. In order to make a $\Delta k a t A$ mutant, oligonucleotide primer pairs KAT1/KATR1 and KATR2/KAT2 (Table 1) were used to PCR-amplify two $0.5 \mathrm{~kb}$ DNA fragments that flanked the $5^{\prime}$ and $3^{\prime}$ ends of katA, respectively, from chromosomal DNA of $S$. aureus 2386. Primers KATR1 and KATR2 carried complementary sequences (underlined in Table 1) that were used to fuse the two fragments by recombinant PCR (Vallejo et al., 1994). The resulting chimeric PCR product was inserted into the PCR2.1 vector, excised using SpeI and $\mathrm{XbaI}$, and cloned into the XbaI site of the pE194ts thermosensitive vector to generate pERkat (Table 1). To construct a $\Delta h l b$ mutant, two $1 \mathrm{~kb}$ DNA fragments that flanked the $5^{\prime}$ and $3^{\prime}$ ends of $h l b$ were amplified using oligonucleotide primer pairs HLB1/HLBR1 and HLB2/HLBR2 (Table 1), fused and cloned into pE194ts as described above, which yielded pERhlb (Table 1). These recombinogenic plasmids were introduced into S. aureus 2386 by protoplast transformation (Götz et al., 1981), and transformants were selected by incubation at $32{ }^{\circ} \mathrm{C}$ on DM3 agar plates that contained $5 \mu \mathrm{g}$ erythromycin $\mathrm{ml}^{-1}$.

For gene deletion, transformants were cultured in BHI broth with erythromycin $\left(5 \mu \mathrm{g} \mathrm{ml}^{-1}\right)$ at $32{ }^{\circ} \mathrm{C}$ overnight. Then, cultures were diluted into fresh medium and grown at $43{ }^{\circ} \mathrm{C}$ (non-permissive for plasmid replication) for $6 \mathrm{~h}$ to induce plasmid integration into the chromosome by homologous recombination. Double crossover and plasmid loss were achieved by regular subculturing at $37{ }^{\circ} \mathrm{C}$ in $\mathrm{BHI}$ broth without erythromycin and plating appropriate dilutions on $\mathrm{BHI}$ agar. The $\Delta k a t A$ mutant was selected for bubble-negative phenotype by the hydrogen peroxide assay (Fig. 1). The $\Delta$ hlb mutant was selected for lack of the outer halo of incomplete haemolysis on sheep blood agar (Fig. 1). Both mutants were tested for sensitivity to erythromycin and, by PCR, for the presence of the deletion using oligonucleotide primer pairs KAT1/KAT2 and HLB1/HLB2.

To obtain the $\Delta k a t A \Delta h l b$ double mutant, pERkat was introduced into the $\Delta h l b$ mutant, using the same protocol as described above.

Complementation of the mutants. To complement the katA mutation, a $1.6 \mathrm{~kb}$ DNA fragment that contained the katA ORF was amplified using the oligonucleotide primer pairs CAT1/CAT2 (Table 1). The amplification product was cloned into pCR2.1, excised by digestion with EcoRI, and then subcloned into the pHpS9 shuttle vector to generate pHkat (Table 1 ). Likewise, to complement the hlb mutation, a $3 \mathrm{~kb}$ DNA fragment that contained the hlb ORF was amplified using the oligonucleotide primer pairs HLB1/HLB2 (Table 1), and directly cloned into the SmaI site of pHpS9 to obtain pHhlb (Table 1). Finally, to complement the double mutant, pHkathlb (Table 1) was constructed by cloning the katA-containing DNA fragment into pHhlb. Plasmids were introduced into the 
Table 1. Bacterial strains, plasmids and primers used in this study

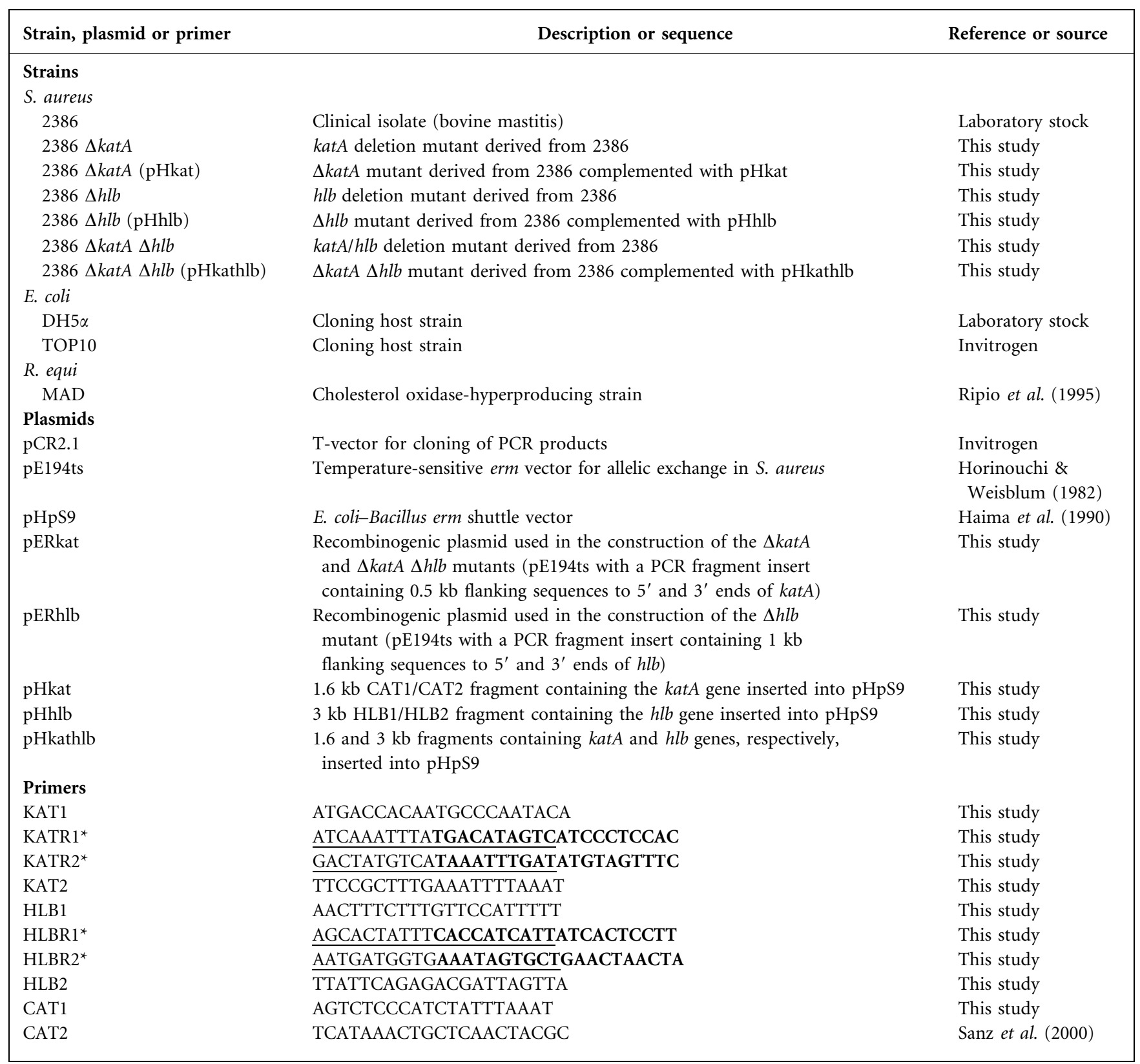

${ }^{*}$ Complementary sequences between KATR1 and KATR2 and between HLBR1 and HLBR2 are underlined. Sequences for target recognition in these primers are indicated by bold type.

mutants by protoplast transformation, and transformants were selected by incubation at $37{ }^{\circ} \mathrm{C}$ on DM3 agar plates supplemented with $5 \mu \mathrm{g}$ erythromycin $\mathrm{ml}^{-1}$. Transformants were also checked for wild-type phenotype restoration.

Biochemical and growth characteristics. In order to test the biochemical profile of the $\Delta k a t A, \Delta h l b$ and $\Delta k a t A \Delta h l b$ mutants in comparison with those of the wild-type strain, API 32 STAPH and API $50 \mathrm{CH}$ systems (bioMérieux) were used. The API $32 \mathrm{STAPH}$ system is based on 32 miniature biochemical tests and is used for the identification of staphylococci to species level. The API $50 \mathrm{CH}$ system contains 50 biochemical tests for the study of the carbohydrate metabolism of micro-organisms. Growth characteristics were determined by monitoring the $\mathrm{OD}_{600}$ of $\mathrm{BHI}$ cultures of each mutant and wild-type strain at $37{ }^{\circ} \mathrm{C}$ with shaking at 175 r.p.m. for $24 \mathrm{~h}$. Optical density measurements were made in a Bio-Rad SmartSpec3000 spectrophotometer with $1.5 \mathrm{ml}$ cuvettes.

Intracellular survival assays. J774A.1, a murine macrophage cell line (ATCC TIB-67), and MAC-T, an established bovine mammary epithelial cell line (Huynh et al., 1991), were used for experiments. J774A.1 cells were grown in RPMI 1640 supplemented with $10 \%$ heat-inactivated fetal bovine serum (FBS) and $1 \%$ Pen/Strep/ Fungizone mix (Biowhittaker). MAC-T cells were cultured in 
(a)
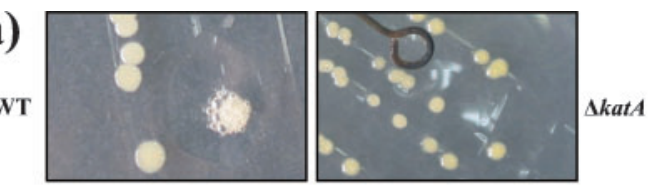

(b)
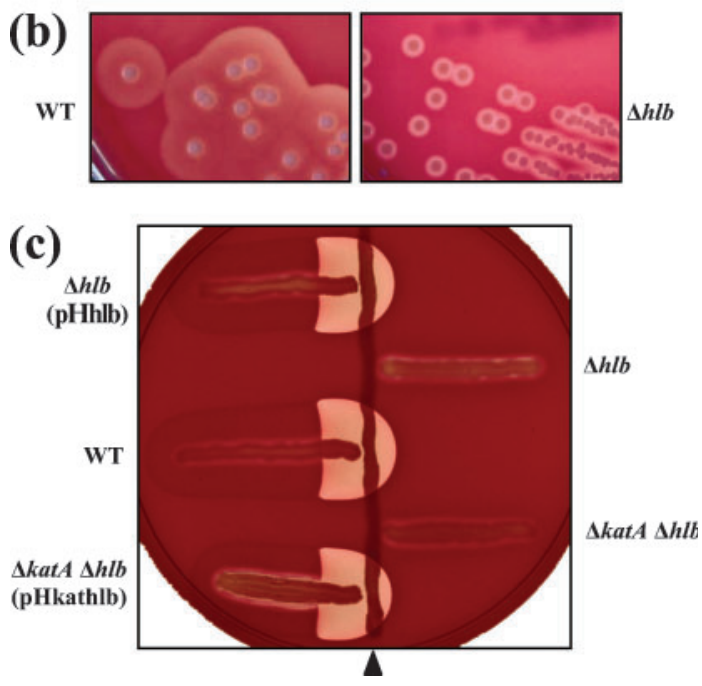

Fig. 1. Phenotypic changes caused by deletion of $k a t A$ and $h / b$ genes. (a) $\Delta k a t A$ mutants showed a bubble-negative phenotype in contact with hydrogen peroxide. (b) $\Delta h / b$ mutants were characterized by absence of the outer halo of incomplete haemolysis on sheep blood agar. (c) Spontaneous and cooperative CAMP-like haemolysis with $R$. equi (vertical streak indicated by an arrowhead) on sheep blood agar. $\Delta h / b$ mutants did not produce a shovelshaped CAMP-like reaction. WT, wild-type strain.

Dulbecco's modified Eagle's medium (DMEM) with $10 \%$ heatinactivated FBS, $5 \mu \mathrm{g}$ insulin $\mathrm{ml}^{-1}, 1 \mu \mathrm{g}$ hydrocortisone $\mathrm{ml}^{-1}$ and $1 \% \mathrm{Pen} / \mathrm{Strep} /$ Fungizone mix. Prior to each experiment, cells were seeded at $3 \times 10^{4}$ cells per well in 24-well tissue-culture plates and grown for $48 \mathrm{~h}$ at $37{ }^{\circ} \mathrm{C}$ with $5 \% \mathrm{CO}_{2}$. Approximately $16 \mathrm{~h}$ before the assay, growth medium was replaced with $1 \mathrm{ml}$ invasion medium (growth medium without antibiotics). Prior to infection, medium was removed and cells were given $0.5 \mathrm{ml}$ fresh invasion medium. Wells were inoculated with $5 \times 10^{5}$ c.f.u. (J774A.1 assay) or $2.5 \times 10^{6}$ c.f.u. (MAC-T assay) of washed bacteria from an overnight culture suspended in $0.5 \mathrm{ml}$ invasion medium. Infected cell monolayers were centrifuged for $5 \mathrm{~min}$ at $450 \mathrm{~g}$ at room temperature, and incubated for $1 \mathrm{~h}$ at $37{ }^{\circ} \mathrm{C}$ with $5 \% \mathrm{CO}_{2}$. Medium was then removed, cell monolayers were washed twice with sterile PBS, and $1 \mathrm{ml}$ invasion medium that contained $100 \mu \mathrm{g}$ gentamicin $\mathrm{ml}^{-1}$ to kill extracellular bacteria was added to each well. After incubation of co-cultures at $37{ }^{\circ} \mathrm{C}$ with $5 \% \mathrm{CO}_{2}$ had continued for 1 (internalized bacteria), 4,8 and $24 \mathrm{~h}$ in the presence of gentamicin, the supernatants were removed and discarded. Cell monolayers were then washed twice with sterile PBS and lysed with $0.2 \%$ Triton X-100 in sterile PBS. Cell lysates were serially diluted 10 -fold and plated in duplicate on BHI agar plates to quantify viable intracellular bacteria. The number of intracellular bacteria at each time point was expressed as a percentage of the number of internalized bacteria.

$\mathbf{L D}_{\mathbf{5 0}}$ determination in mice. $\mathrm{LD}_{50}$ was calculated by employing the method of Reed \& Muench (1938). Groups of five female Swiss mice, 4 weeks old, were inoculated intraperitoneally with 10 -fold serial dilutions of bacterial suspension (doses ranged from $1 \times 10^{6}$ to $1 \times 10^{11}$ c.f.u. $\mathrm{ml}^{-1}$ ) in $0.4 \mathrm{ml}$ sterile PBS. The precise inoculum was confirmed by serial dilution and counting on BHI agar plates. Inoculated mice were monitored for death every $24 \mathrm{~h}$ for 7 days.

Competitive index $(\mathrm{Cl})$ determination in a murine skin abscess model. CI was measured as described previously (Benton et al., 2004) in an established murine abscess model of infection (Horsburgh et al., 2001), with the following modifications. Mutant and wild-type strains were separately grown to stationary phase in BHI broth, harvested, washed and resuspended in sterile PBS. Then, each single mutant was mixed with the wild-type strain at a concentration of $4 \times 10^{8}$ c.f.u. $\mathrm{ml}^{-1}$ ( $1: 1$ ratio, $8 \times 10^{8}$ c.f.u. $\mathrm{ml}^{-1}$ total), and the double mutant was mixed with the wild-type strain in a $10: 1$ ratio at concentrations of $8 \times 10^{9}$ and $8 \times 10^{8}$ c.f.u. $\mathrm{ml}^{-1}\left(8.8 \times 10^{9}\right.$ c.f.u. $\mathrm{ml}^{-1}$ total $)$, respectively. To determine the exact input ratio, serial dilutions of these mixtures were plated on BHI agar or Columbia agar with $5 \%$ sheep blood, to distinguish between mutant and wild-type strains by the hydrogen peroxide assay or the haemolytic phenotype, respectively. Groups of three female 6-8-week-old $\mathrm{BALB} / \mathrm{c}$ mice were inoculated subcutaneously on the back with $0.2 \mathrm{ml}$ mutant/wild-type mixtures. After 7 days, mice were euthanized with $\mathrm{CO}_{2}$, abscesses were aseptically opened, and the contents were homogenized in $1 \mathrm{ml}$ sterile ice-cold PBS. Output ratios were determined by plating serial dilutions of these homogenates, as described above, to calculate input ratio. The $\mathrm{CI}$ for each mutant was calculated as the ratio between the mutant and the wild-type strain in the output (abscess content) divided by the ratio in the input (initial inoculum).

Experimental intramammary infections in ewes. The experimental infection was induced as described previously (Cucarella et al., 2002). At 20 to 25 days after parturition, a group of six healthy lactating Manchego ewes was inoculated with $5 \times 10^{2}$ c.f.u. of the wild-type strain, and three groups of three ewes were inoculated with different doses of the $\Delta k a t A \Delta h l b$ double mutant $\left(1.5 \times 10^{3}, 1.5 \times 10^{4}\right.$ and $1.7 \times 10^{5}$ c.f.u.) in $1 \mathrm{ml}$ sterile PBS. Ewes were separated from their lambs $2 \mathrm{~h}$ before the inoculation to guarantee the presence of milk (as a natural lubricant) in the teat duct at the time of inoculation. After the teats were disinfected with $70 \%$ ethanol, the bacterial inoculum was introduced into both glands through a 21gauge cannula. Following inoculation, because suckling can favour the removal of the bacteria, lambs were separated from their mothers for $3 \mathrm{~h}$ to increase the bacterial colonization of the mammary gland. Milk samples for bacteriological analysis and somatic cell counts (SCCs) were obtained prior to inoculation, once a day for the first week after inoculation, every 2 days and every 3 days in the second and third weeks, respectively, and at 28 days. SCCs were analysed at the Centro de Selección y Reproducción Animal-Instituto Madrileño de Investigación y Desarrollo Rural, Agrario y Alimentario CENSYRA-IMIDRA Dairy Control Laboratory (Madrid, Spain). For bacteriological analysis, serial dilutions of milk samples were placed on Baird-Parker agar and Columbia agar with $5 \%$ sheep blood. Rectal temperature was regularly recorded from day 2 before inoculation to 10 days post-infection. A detailed clinical examination of the mammary gland was carried out during the same time interval as milk sampling.

Experimental subcutaneous infection in lambs. Groups of two 8-10-week-old Manchego lambs were simultaneously inoculated by the subcutaneous route in the right armpit, just behind the elbow joint, with the wild-type strain, and in the left armpit with the same dose of the $\Delta$ katA $\Delta$ hlb double mutant. Doses of $1.5 \times 10^{5}, 1.1 \times 10^{7}$ and $1.2 \times 10^{8}$ c.f.u. in $0.2 \mathrm{ml}$ sterile PBS were used. Infected animals were clinically examined for the 3 weeks following inoculation, paying special attention to the local reactions at the inoculation sites and to any inflammation of the lymph nodes that drained the experimental 
area. When an abscess appeared at the inoculation site, a sample was obtained for bacteriological analysis.

Ethical considerations. All experiments with live animals were performed under the guidelines of the European Community (86/ 609) and were approved by the Ethical Committee for the Animal Experimentation, CEA, of the University Complutense of Madrid.

Statistical analysis. Data were analysed by a two-tailed Student's $t$ test for unpaired data to determine statistically significant differences. Differences were considered statistically significant when $P$ was $<0.05$ in all cases. Analyses were made with the help of GraphPad InStat software (version 3.05).

\section{RESULTS}

\section{Construction and characterization of $S$. aureus kat $A$ and $h / b$ mutants}

In order to determine the potential role of catalase and beta-toxin in S. aureus pathogenesis we obtained single and double mutants by deleting the katA and hlb genes in the bovine clinical isolate $S$. aureus 2386. Deletion of the katA gene caused a bubble-negative phenotype in contact with hydrogen peroxide (Fig. 1a). The $\Delta$ hlb mutation was characterized by a lack of the outer halo of incomplete haemolysis (Fig. 1b) and a negative shovel-shaped cooperative Christie-Atkins-Munch-Petersen (CAMP)like haemolysis in the presence of Rhodococcus equi (Fig. 1c) on sheep blood agar. Compared with the wild-type strain, none of the three mutants showed any difference in biochemical features or utilization of a panel of 50 carbohydrates analysed by API 32 STAPH and API 50 $\mathrm{CH}$, respectively. In addition, deletion of the katA and/or hlb gene had no apparent influence on in vitro growth of $S$. aureus, since the growth curves of the wild-type and mutant strains were similar (data not shown). Therefore, any differences in the behaviour of the mutants could not be attributed to differences in housekeeping gene activities or growth capability. Finally, to confirm that the deletion of the katA or hlb genes was responsible for the observed phenotypes, a genetic complementation study was performed. As expected, complementation of the mutants with plasmids that carried the katA and/or hlb genes restored the wild-type phenotype (data not shown).

\section{Intracellular survival of the $\Delta k a t A, \Delta h / b$ and $\Delta k a t A$ $\Delta h / b$ mutants}

To investigate whether catalase and beta-toxin are involved in intracellular survival of $S$. aureus, we examined the ability of the mutants, complemented mutants and wild-type strain to survive inside two different cell types. We specifically used the murine macrophage-like cell line J774A.1 and the bovine mammary epithelial cell line MAC-T.

(i) J774A.1 assay. These cells retain the ability to display a respiratory burst and are quite permissive towards a variety of intracellular pathogens (Day et al., 2000; Seral et al., 2003). Intracellular viability of the mutants and the wildtype strain in J774A.1 cells was determined over a period of $24 \mathrm{~h}$. All strains exhibited a decrease in the number of viable bacteria after phagocytosis (Fig. 2a). Intracellular survival of the $\Delta k a t A$ and $\Delta h l b$ mutants was not substantially different to that of the wild-type strain. However, the $\Delta k a t A \Delta h l b$ mutant showed significantly higher survival rates than the wild-type strain and the single mutants $(P<0.01$ at 4 and $8 \mathrm{~h} ; P<0.05$ at $24 \mathrm{~h})$. All complemented mutants had a behaviour similar to that of the wild-type strain (Fig. 2a).

(ii) MAC-T assay. MAC-T cells have been used in numerous studies to characterize the ability of $S$. aureus (a)

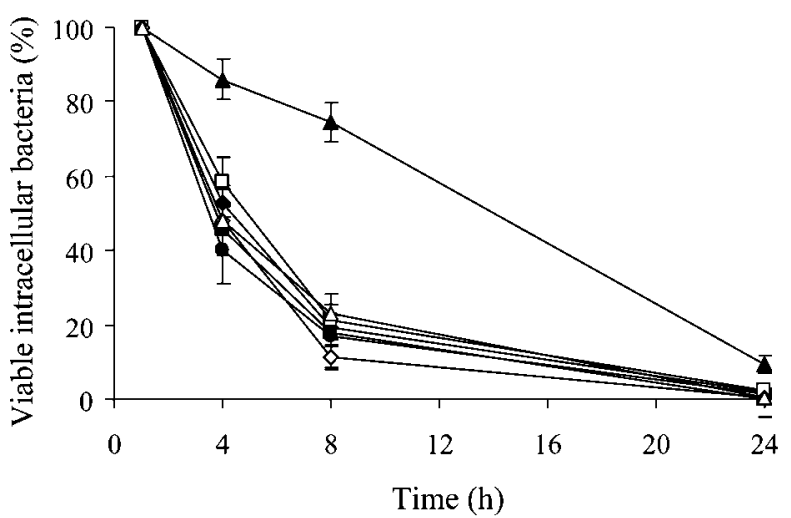

(b)

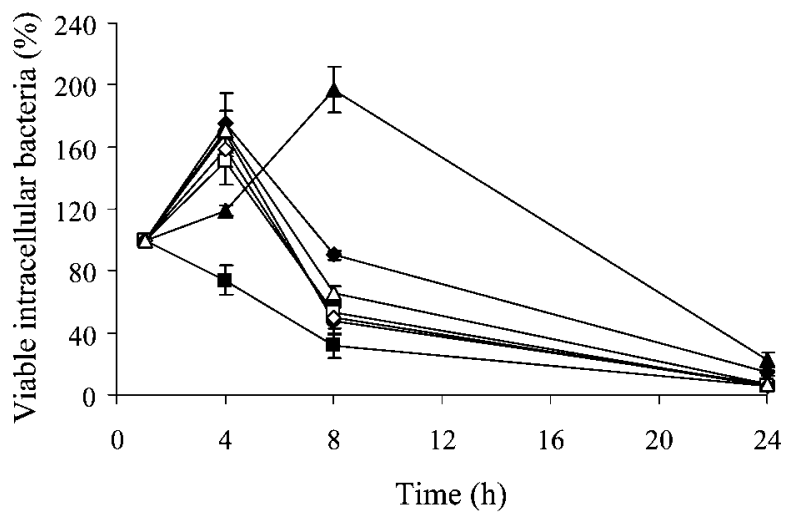

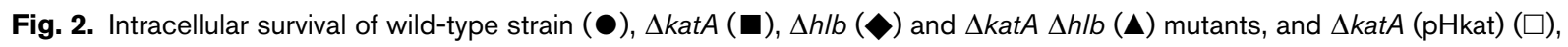
$\Delta h / b(\mathrm{pHhlb})(\diamond)$ and $\Delta$ katA $\Delta h / b(\mathrm{pHkathlb})(\triangle)$ complemented mutants in J774A.1 (a) and MAC-T (b) cell lines. Numbers of viable intracellular bacteria at 4,8 and $24 \mathrm{~h}$ are expressed as a percentage of internalized bacteria and represent the mean \pm SEM of at least three independent experiments. 
to invade and survive within eukaryotic cells (Bayles et al., 1998; Qazi et al., 2001; Wesson et al., 1998). Wild-type S. aureus 2386 was internalized by and proliferated inside MAC-T cells (Fig. 2b). Thus, the number of viable intracellular bacteria at $4 \mathrm{~h}$ was $\sim 1.7$-fold higher than the number of internalized bacteria. After this initial increase in titre, the viability of the wild-type strain gradually declined, and reached about $7.3 \%$ of that of the internalized bacteria at $24 \mathrm{~h}$. Unlike the wild-type strain, the $\Delta k a t A$ mutant did not exhibit an early increase in the number of viable bacteria, and viability diminished after internalization (Fig. 2b). However, despite this apparent lack of intracellular multiplication, the survival rates of the $\Delta k a t A$ mutant at 8 and $24 \mathrm{~h}$ were similar to those of the wild-type strain. With respect to the $\Delta h l b$ mutant, it initially had similar kinetics to those of the wild-type strain (Fig. 2b). The $\Delta$ hlb mutant grew intracellularly during the first $4 \mathrm{~h}$, and then progressively declined, but it showed a significantly higher intracellular survival at 8 and $24 \mathrm{~h}$ ( $P=0.0043$ and $P=0.0206$, respectively) than the wild-type strain. Finally, the $\Delta k a t A \Delta h l b$ mutant also proliferated intracellularly, but its growth was delayed in comparison with that of the wild-type strain (Fig. 2b). Thus, the number of intracellular bacteria increased almost twofold within the first $8 \mathrm{~h}$. Together with the delayed intracellular proliferation, the double mutant showed a significantly greater persistence level in MAC-T cells compared with the wild-type strain $(P=0.0001$ at $8 \mathrm{~h} ; P=0.0207$ at $24 \mathrm{~h})$. In all cases, complementation with plasmids that carried the deleted gene(s) returned to the mutants the characteristics observed in the wild-type strain (Fig. 2b).

\section{Virulence of the mutants in murine models.}

(i) $\mathrm{LD}_{\mathbf{5 0}}$ determinations. To analyse whether katA or $h l b$ has a role in the virulence of $S$. aureus, $\mathrm{LD}_{50}$ assays in mice were performed. Mice were infected intraperitoneally. As shown in Table 2, the mean $\mathrm{LD}_{50}$ for the $\Delta$ kat $A$ mutant was lower than that of the wild-type, but this difference was not statistically significant. Likewise, no significant differences in virulence were observed between the $\Delta h l b$ mutant and the wild-type strain in this model. In contrast, the double

Table 2. $\mathrm{LD}_{50}$ determination in mice

\begin{tabular}{|lcc|}
\hline Strain & LD $_{\mathbf{5 0}}{ }^{*}$ & $\boldsymbol{P}^{\text {value }} \dagger$ \\
\hline WT & $2.80 \pm 1.35 \times 10^{9}$ & - \\
$\Delta$ katA & $5.68 \pm 0.78 \times 10^{8}$ & 0.1735 \\
$\Delta$ katA (pHkat) & $4.26 \pm 0.43 \times 10^{8}$ & 0.1531 \\
$\Delta$ hlb & $3.75 \pm 2.03 \times 10^{9}$ & 0.7143 \\
$\Delta$ hlb (pHhlb) & $1.00 \pm 0.34 \times 10^{8}$ & 0.1157 \\
$\Delta$ katA $\Delta$ hlb & $1.41 \pm 0.27 \times 10^{10}$ & 0.0199 \\
$\Delta$ katA $\Delta$ hlb (pHkathlb) & $5.77 \pm 1.80 \times 10^{8}$ & 0.1773 \\
\hline
\end{tabular}

${ }^{\star}$ Data represent the mean \pm SEM from three independent experiments. $\dagger \mathrm{LD}_{50}$ values for mutants or complemented mutants were compared with that for the wild-type (WT) strain.
$\Delta k a t A \Delta h l b$ mutant was five times less virulent than the wild-type strain in this model and the differences observed were statistically significant $(P=0.0199)$. We also observed a statistically significant reduction in the virulence of the double mutant by comparison with both the $\Delta$ katA $(P=0.0074)$ and the $\Delta$ hlb $\quad(P=0.0374)$ mutants. Furthermore, complementation restored the virulence of the double mutant (Table 2).

(ii) $\mathrm{Cl}$ determination in a murine skin abscess model. CI is a sensitive measure of the relative degree of virulence attenuation of a particular mutant in mixed infections with the wild-type strain (Benton et al., 2004). To provide more data about the virulence of the mutants, CI was determined in vivo, using an established mouse subcutaneous model of infection (Horsburgh et al., 2001). As with the results of the $\mathrm{LD}_{50}$ assay, the $\Delta k a t A$ and $\Delta h l b$ mutants were not attenuated in this model (Table 3). Only the $\Delta k a t A \Delta h l b$ mutant was out-competed by the wild-type strain, consistent with significant attenuation of the mutant compared with the wild-type strain (Table 3). Furthermore, since CI values lower than 0.4 are considered to represent defects in virulence (RamosMorales et al., 2003), the double mutant was severely attenuated in this model $(\mathrm{CI}=0.036)$.

\section{Virulence of the $\Delta k a t A \Delta h / b$ mutant in ovine models}

In order to further characterize the virulence potential of the $\Delta k a t A \Delta h l b$ mutant, we induced intramammary and subcutaneous infections in ewes and lambs.

(i) Experimental intramammary infections in ewes. The wild-type S. aureus 2386 strain was highly virulent in this model. Five out of the six ewes inoculated with 500 c.f.u. developed clinical mastitis with different degrees of severity (Table 4). Thus, two ewes developed a gangrenous mastitis in both mammary glands and they were euthanized at 48$72 \mathrm{~h}$ post-infection. In another two ewes, the wild-type strain caused severe mastitis in one mammary gland and mild mastitis in the other. One ewe developed mild mastitis in one gland, whereas in the other, mastitis was subclinical, and in the remaining ewe the experimental infection was subclinical in both glands (Table 4).

The clinical signs observed had a direct correlation with infection severity. In ewes with clinical mastitis, mammary glands were swollen, hard and painful, and even cyanotic in cases of gangrenous mastitis. Moreover, these glands produced abnormal milk, with clots and even blood in the most serious cases. Ewes also exhibited an increase in rectal temperature and a decrease in appetite. Elevated rectal temperatures were detected at 24 and $48 \mathrm{~h}$ postinfection, and reached a maximum at $24 \mathrm{~h}$ (Fig. 3a).

Bacteria were isolated from all the inoculated mammary glands from day 1 post-infection until the end of the experimental period (Fig. 3b). The number of bacteria in 
Table 3. $\mathrm{Cl}$ in mice

\begin{tabular}{|lcccc|}
\hline Strains compared & Challenge route & Inoculum ratio & CI $^{\star}$ & Attenuation $\dagger$ \\
\hline$\Delta k a t A$ versus WT & Subcutaneous & $1: 1$ & $1.411 \pm 0.154$ & No \\
$\Delta h l b$ versus WT & Subcutaneous & $1: 1$ & $0.837 \pm 0.178$ & No \\
$\Delta k a t A \Delta h l b$ versus WT & Subcutaneous & $10: 1 \neq$ & $0.036 \pm 0.004$ & Yes \\
\hline
\end{tabular}

${ }^{\star} \mathrm{CI}$ is the ratio between the mutant and the WT S. aureus in the output (bacteria recovered from abscess content homogenates, 7 days after infection) divided by their ratio in the input (initial inoculum). Data represent the mean \pm SEM obtained from a minimum of five mice from three independent experiments.

$\dagger$ Mutants are considered to be attenuated when CI <0.4 (Ramos-Morales et al., 2003).

\#Inoculum ratio was increased because the $1: 1$ ratio did not allow recovery of mutant bacteria from the lesion.

milk was in general greater in the mammary glands with clinical mastitis. Mean values were very high $\left(\sim 10^{8}\right.$ c.f.u. $\mathrm{ml}^{-1}$ ) and relatively constant over the 28 days of the experiment. Furthermore, the SCCs increased significantly in response to infection with the wild-type strain and remained elevated until the end of the experiment (Fig. 3c).

Unlike the wild-type strain, the $\Delta k a t A \Delta h l b$ mutant did not cause any clinical mastitis in the inoculated udders, not even with the highest dose used, almost 350 times greater than that of the wild-type strain (Table 4). Moreover, there were no apparent differences in the responses of the animals to the different doses of mutant used. Apart from slight swelling at $24 \mathrm{~h}$ post-infection in eight out of the 18 mammary glands inoculated, and a very slight increase in rectal temperature, no other clinical alterations were observed. The highest temperature $\left(39.8 \pm 0.20{ }^{\circ} \mathrm{C}\right)$ was detected at $48 \mathrm{~h}$ post-infection (Fig. 3a). and it was significantly lower than that reached $\left(40.82 \pm 0.34{ }^{\circ} \mathrm{C}\right)$ at $24 \mathrm{~h}$ post-infection in the ewes infected with the wild-type strain $(P=0.0173)$.

Like the wild-type strain, the $\Delta k a t A \Delta h l b$ mutant infected all the inoculated mammary glands and it was shed in milk throughout the experiment (Fig. 3b). However, overall bacterial counts in milk were significantly lower than those found with the wild-type strain $(P<0.05)$. SCCs also increased greatly after infection with the double mutant and remained high over the entire period of the experiment (Fig. 3c). SCCs were generally lower than those reached in the mammary glands infected with the wild-type strain; however, the differences were not statistically significant.

(ii) Experimental subcutaneous infection in lambs. Three groups of two lambs were used for the assay. Animals were simultaneously inoculated in the right armpit with the wild-type strain, and in the left one with the same dose of the $\Delta$ kat $A \Delta h l b$ mutant (Table 5). Lambs infected with the lowest dose $\left(1.5 \times 10^{5}\right.$ c.f.u. $)$ did not show clinical alterations at the inoculation sites or in the regional lymph nodes. The lambs inoculated with $1.1 \times 10^{7}$ and $1.2 \times 10^{8}$ c.f.u. of both strains showed a similar response to the experimental infections. Thus, no local alterations were detected at the left inoculation site or in the left superficial cervical lymph node in these lambs (Table 5). In contrast, the wild-type strain caused a clear local inflammatory response at $24-48 \mathrm{~h}$ post-infection, which led to abscess development in all lambs. Abscesses reached a diameter of $\sim 2 \mathrm{~cm}$ at 4-6 days post-infection, then gradually regressed, and were practically resolved at 20 days post-infection. Moreover, the wild-type strain also caused enlargement of the right superficial cervical lymph node in these animals.

Table 4. Experimental intramammary infection in ewes

\begin{tabular}{|c|c|c|c|c|c|c|c|}
\hline \multirow[t]{3}{*}{ Group $(n)^{*}$} & \multirow[t]{3}{*}{ Strain } & \multirow[t]{3}{*}{ Dose (c.f.u.) } & \multirow{3}{*}{$\begin{array}{c}\text { Number of } \\
\text { mammary glands } \\
\text { infected }\end{array}$} & \multicolumn{4}{|c|}{ Severity of intramammary infection $\dagger$} \\
\hline & & & & \multirow[t]{2}{*}{ Subclinical } & \multicolumn{3}{|c|}{ Clinical } \\
\hline & & & & & Mild & Severe & Gangrenous \\
\hline$A(6)$ & WT & $5 \times 10^{2}$ & 12 & 3 & 3 & 2 & 4 \\
\hline $\mathrm{B}(3)$ & $\Delta k a t A \Delta h l b$ & $1.5 \times 10^{3}$ & 6 & 6 & - & - & - \\
\hline C (3) & $\Delta k a t A \Delta h l b$ & $1.5 \times 10^{4}$ & 6 & 6 & - & - & - \\
\hline $\mathrm{D}(3)$ & $\Delta k a t A \Delta h l b$ & $1.7 \times 10^{5}$ & 6 & 6 & - & - & - \\
\hline
\end{tabular}

${ }^{*} n$ refers to the number of healthy lactating Manchego ewes inoculated in each group.

$\dagger$ Animals were clinically examined for 4 weeks. 


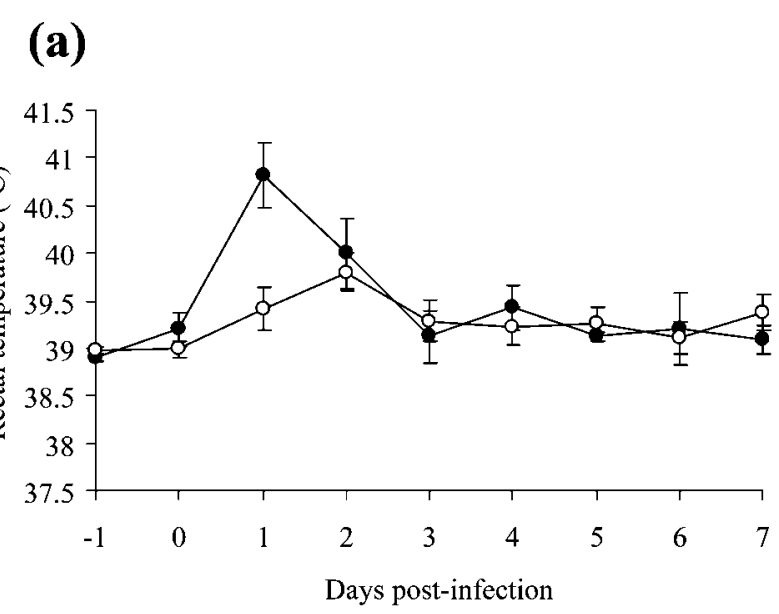

(b)

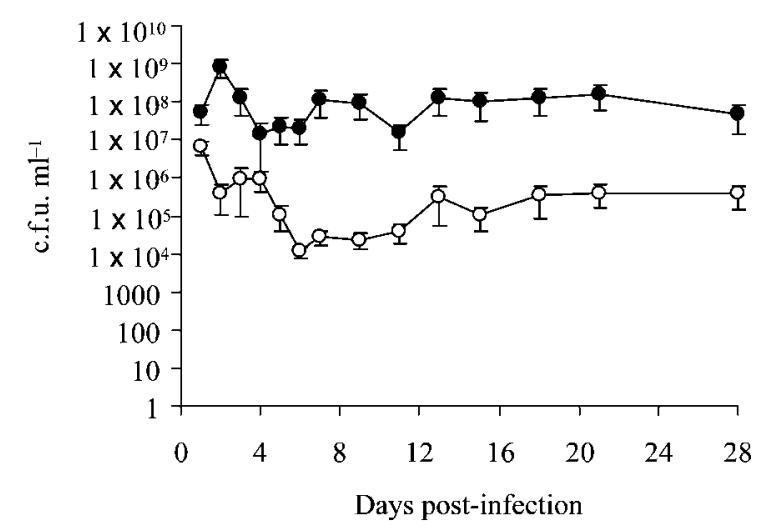

(c)

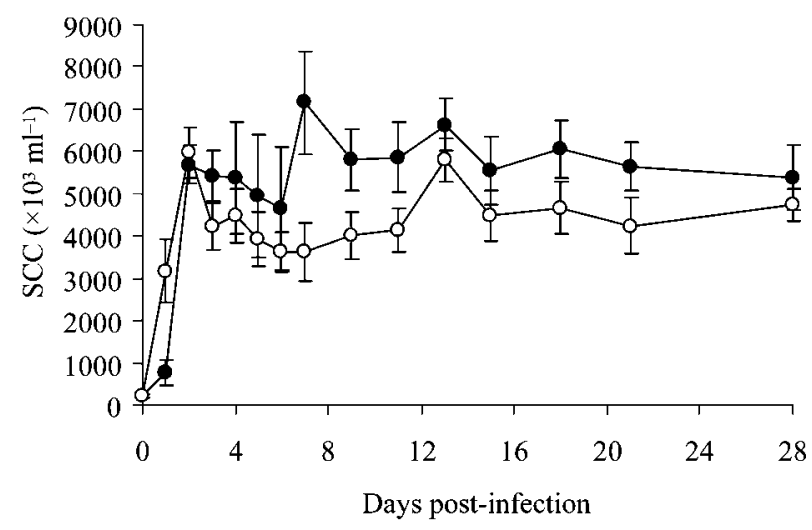

Fig. 3. Rectal temperature (a), bacterial shedding in milk (b) and SCCs in milk (c) in ewes infected with wild-type $S$. aureus ( $(\bullet)$ and the $\Delta k a t A \Delta h l b$ mutant $(\bigcirc)$. Data represent mean \pm SEM. Mean values for the $\Delta k a t A \Delta h l b$ mutant were calculated from the data for all infected ewes, regardless of the dose used.

\section{DISCUSSION}

The purpose of this study was to investigate the potential role of catalase and beta-toxin in the intracellular survival, and consequently virulence, of $S$. aureus. With this aim, single and double mutants of $k a t A$ and $h l b$ genes were created by gene deletion.

S. aureus is not generally considered to be a major intracellular pathogen. However, it is well documented that $S$. aureus adheres to, easily invades and survives within non-professional (Bayles et al., 1998; Menzies \& Kourteva, 1998; Wesson et al., 1998) and professional phagocytes (Brouillette et al., 2003; Hébert et al., 2000). Factors influencing the internalization of $S$. aureus have frequently been investigated (Alexander \& Hudson, 2001), but little is known about those that are necessary for its intracellular survival.

Phagocytosis by polymorphonuclear neutrophils (PMNs) and macrophages is considered to be the first and main defence mechanism of the host against $S$. aureus invasion. Bactericidal mechanisms of phagocytic cells include the production of ROS, such as superoxide anion, hydrogen peroxide and hydroxyl radicals (Cabiscol et al., 2000). However, the generation of ROS is not an exclusive prerogative of professional phagocytes, and it has also been described in non-phagocytic cells (Meier, 2001). Therefore, enzymes implicated in oxidative stress resistance could play an important role in the survival of $S$. aureus inside both phagocytic and non-phagocytic cells. However, in our experiments, catalase did not contribute to the survival of S. aureus within J774A.1 macrophages. This indicates either that the production of ROS by these cells, which retain the ability to display a respiratory burst, is not involved in the killing of $S$. aureus or that the $\Delta k a t A$ mutant compensates for the lack of catalase activity by the expression of other oxidative stress-resistance factors such as alkyl hydroperoxide reductase, which has been demonstrated to have compensatory roles with catalase in cellular physiology (Cosgrove et al., 2007). Catalase also did not significantly participate in the long-term survival of $S$. aureus in MAC-T cells, although it was required for the intracellular proliferation of the bacterium during the initial hours after cell invasion. This finding reveals differences between J774A.1 and MAC-T cells in the bactericidal mechanisms against $S$. aureus, at least in the early stage of intracellular infection.

Current knowledge of the role of bacterial sphingomyelinases in intracellular pathogenesis remains limited. In Listeria ivanovii, a sphingomyelinase similar to beta-toxin, SmcL, seems to promote intracellular proliferation of bacteria in bovine epithelial cells by mediating disruption of the phagocytic vacuole and the release of bacteria into the cytosol (González-Zorn et al., 1999). Earlier work has demonstrated that intracellular $S$. aureus escapes from endosomes and then multiplies within the cytoplasm in MAC-T cells (Bayles et al., 1998; Qazi et al., 2001; Shompole et al., 2003). Moreover, staphylococcal haemolysins are involved in endosome rupture and subsequent intracellular replication of $S$. aureus (Shompole et al., 2003). In our study, the lack of beta-toxin did not modify the proliferation of $S$. aureus in MAC-T cells during the 
Table 5. Experimental subcutaneous infection in lambs

\begin{tabular}{|lcccc|}
\hline Group $^{*}$ & Dose (c.f.u.) & Strain & $\begin{array}{c}\text { Superficial cervical } \\
\text { lymph node } \dagger\end{array}$ & $\begin{array}{c}\text { Abscess in the } \\
\text { inoculation site } \dagger\end{array}$ \\
\hline A & $1.5 \times 10^{5}$ & WT & Normal & No \\
& & $\Delta k a t A \Delta h l b$ & Normal & No \\
B & $1.1 \times 10^{7}$ & WT & Increased & Yes \\
& & $\Delta k a t A \Delta h l b$ & Normal & No \\
C & $1.2 \times 10^{8}$ & WT & Increased & Yes \\
& & $\Delta k a t A \Delta h l b$ & Normal & No \\
& & &
\end{tabular}

${ }^{\star}$ Groups of two 8-10-week-old Manchego lambs were simultaneously inoculated by the subcutaneous route in the right armpit with the WT S. aureus and in the left armpit with the same dose of the $\Delta k a t A \Delta h l b$ mutant.

$\dagger$ Animals were clinically examined for 3 weeks. Clinical responses were similar in both lambs of each group.

first $4 \mathrm{~h}$ post-infection. Therefore, it is possible that the remaining haemolysins were sufficient to allow the release of $S$. aureus from the endosome in these cells. Nevertheless, the absence of beta-toxin, which had no effect on intracellular survival of $S$. aureus in murine J774A.1 macrophages, caused an increase in bacterial persistence in bovine MAC-T epithelial cells at 8 and $24 \mathrm{~h}$ postinfection. This divergence might have been caused by differences in the sphingomyelin content of these cells. Thus, a correlation has been observed between membrane sphingomyelin content and the susceptibility of erythrocytes to beta-toxin; therefore, only erythrocytes from ruminants, which have the highest content of all mammals, are highly susceptible (Titball, 1993). The increased persistence of the $\Delta h l b$ mutant in MAC-T cells in comparison with the wild-type strain could have been a result of lower cytolytic activity, which protected the mutant from the gentamicin present in the extracellular medium. Our results are in agreement with previous studies in which a lack of alpha-toxin (Vann \& Proctor, 1988) or a decreased production of haemolysins (von Eiff et al., 1997; Wesson et al., 1998) in S. aureus were associated with an increase in its intracellular survival.

Interestingly, the behaviour of the $\Delta k a t A \Delta h l b$ mutant in the intracellular survival assays was quite different from that of the single mutants. Thus, the simultaneous lack of catalase and beta-toxin caused a notable increase in the survival of $S$. aureus within J774A.1 macrophages at all the three time points examined, and within MAC-T cells at 8 and $24 \mathrm{~h}$ post-infection. Moreover, in MAC-T cells, a delay in the proliferation of the double mutant in comparison with the wild-type strain and the $\Delta h l b$ mutant was observed. The increased survival of the double mutant could initially be attributed to a higher resistance to the bactericidal activity of the cells, and this would imply increased virulence of the double mutant. However, this interpretation, which could be considered when the intracellular assays are analysed in isolation, clearly contrasts with the results obtained in all the experimental infection models used, which undoubtedly showed that the combined mutation leads to a dramatic reduction in virulence. Therefore, the in vitro increased intracellular persistence of the double mutant could be a consequence of the diminished cytotoxicity of the bacterium, which would have delayed death of the infected cells. The mechanism by which catalase and beta-toxin synergistically contribute to intracellular pathogenesis of $S$. aureus in J774A.1 and MAC-T cells is not evident. Further studies on the possible interaction between these two proteins during the intracellular infection of $S$. aureus are needed to determine this mechanism and to establish how the increased intracellular persistence is connected with the attenuation in animal models. Nevertheless, the results of the experimental infections allow us to hypothesize that in vivo the simultaneous lack of catalase and beta-toxin results in a limited capacity of the mutant to proliferate and spread.

The changes observed in the intracellular behaviour of the mutants may have altered their virulence; therefore, we decided to use two different murine models to investigate this question. Systemic and abscess models allowed us to establish the ability of a bacterium to survive in two distinct host environments. The systemic model involves the adaptation of bacteria to the host environment, survival of the host immune response, dissemination and colonization, and persistence within organs. The abscess model, in contrast, does not require dissemination to organs. Furthermore, during abscess formation, bacterial growth is reduced by influx of neutrophils, as well as oxygen and nutrient limitation.

Catalase has traditionally been implicated as a virulence determinant in S. aureus (Kanafani \& Martin, 1985; Mandell, 1975). However, recent studies with S. aureus katA mutants have revealed no differences in virulence from the corresponding wild-type strains in murine models of infection (Cosgrove et al., 2007; Horsburgh et al., 2001). The results of this study supply further experimental evidence that catalase is not required for complete virulence of $S$. aureus, at least not in the murine models used.

The role of beta-toxin in staphylococcal infections is not clear, since divergent results have been reported in various 
experimental models with beta-toxin mutants (Bramley et al., 1989; Nilsson et al., 1999; O'Callaghan et al., 1997). In our study, the virulence of the $\Delta h l b$ mutant was not significantly different from that of the wild-type strain in the two murine models, which agrees with the results of the intracellular survival experiment with the murine cell line J774A.1, which also showed no differences. The finding that beta-toxin does not seem to have any effect on the pathogenesis of S. aureus for mice does not allow us to rule out the possibility that this toxin plays an important role in intramammary infections caused by $S$. aureus, especially in ruminants. Beta-toxin is consistently produced by $S$. aureus strains isolated from bovine mastitis; therefore, it has been suggested that it is an active virulence factor in the pathogenesis of bovine $S$. aureus mastitis (Larsen et al., 2002). This hypothesis is supported by the fact discussed above that the lack of beta-toxin caused increased persistence of $S$. aureus in bovine MAC-T cells, possibly due to lower cytolytic activity and a potential relationship with the high membrane content of sphingomyelin in ruminant cells.

Although catalase and beta-toxin per se did not significantly contribute to the virulence of $S$. aureus, the $\Delta k a t A$ $\Delta h l b$ mutant was clearly attenuated in the two murine models of infection. The in vivo results therefore do not support the view that a longer intracellular persistence in vitro, even in macrophage-like cells, gives rise to increased virulence. On the contrary, the results of the experimental infections clearly indicate that in vivo the double mutant is more susceptible to the host defence mechanisms than the wild-type and single mutants, and correlate well with the interpretation that the double mutant has a notably diminished virulence for cells. They also demonstrate the multifactorial nature of the pathogenesis of $S$. aureus, and hence the necessity to establish how potential virulence factors interact in causing disease.

The results of the experimental infection in mice with the $\Delta k a t A \Delta h l b$ mutant led us to further investigate the virulence of the double mutant in two different ovine models of infection. Marked attenuation in the virulence of the $\Delta$ katA $\Delta h l b$ mutant was observed in experimental intramammary infection in ewes, based on clinical manifestations. In this model, the wild-type strain was extremely virulent, since 500 c.f.u. caused very severe mastitis in most animals, whereas the double mutant was not able to cause clinical mastitis in the infected ewes, not even in those inoculated with $1.7 \times 10^{5}$ c.f.u. The double mutant, however, caused subclinical mastitis in all the infected udders, as demonstrated by shedding of bacteria in milk and increased SCCs, which means that the $\Delta k a t A \Delta h l b$ mutant still retained the capacity to invade, colonize and grow in the mammary gland. The attenuation of the double mutant seen in the model of subcutaneous infection in lambs was even more evident. Indeed, the two higher doses of the mutant did not produce any local alteration at the inoculation site, while the corresponding dose of the wildtype caused local inflammation that led to the development of abscesses in all cases.
S. aureus is the most common cause of intramammary infections in ruminants, which result in important economic losses for the dairy industry (Sutra \& Poutrel, 1994). The use as live vaccines of attenuated bacteria, such as the $\Delta k a t A \Delta h l b$ mutant, might be a good strategy to prevent $S$. aureus mastitis.

\section{ACKNOWLEDGEMENTS}

This research was supported by grants from the Spanish Ministry of Education and Science (MEC) (AGF98-0743), Universidad Complutense-Comunidad de Madrid (920338) and Laboratorios Hipra, SA (470/2005). We thank Kenneth W. Bayles, University of Nebraska, for the gift of MAC-T cells, A. Vindel (Instituto de Salud Carlos III) for determining the spa and ST type, and R. Sánchez and E. Neves for their technical support.

\section{REFERENCES}

Aarestrup, F. M., Larsen, H. D., Eriksen, N. H., Elsberg, C. S. \& Jensen, N. E. (1999). Frequency of alpha- and beta-haemolysin in Staphylococcus aureus of bovine and human origin. A comparison between pheno- and genotype and variation in phenotypic expression. APMIS 107, 425-430.

Alexander, E. H. \& Hudson, M. C. (2001). Factors influencing the internalization of Staphylococcus aureus and impacts on the course of infections in humans. Appl Microbiol Biotechnol 56, 361-366.

Ausubel, F. M., Brent, R., Kingston, R. E., Moore, D. D., Seidman, J. G., Smith, J. A. \& Struhl, K. (1992). Current Protocols in Molecular Biology. New York: Green Publishing Associates and WileyInterscience.

Basu, M., Czinn, S. J. \& Blanchard, T. G. (2004). Absence of catalase reduces long-term survival of Helicobacter pylori in macrophage phagosomes. Helicobacter 9, 211-216.

Bayles, K. W., Wesson, C. A., Liou, L. E., Fox, L. K., Bohach, G. A. \& Trumble, W. R. (1998). Intracellular Staphylococcus aureus escapes the endosome and induces apoptosis in epithelial cells. Infect Immun 66, 336-342.

Benton, B. M., Zhang, J. P., Bond, S., Pope, C., Christian, T., Lee, L., Winterberg, K. M., Schmid, M. B. \& Buysse, J. M. (2004). Large-scale identification of genes required for full virulence of Staphylococcus aureus. J Bacteriol 186, 8478-8489.

Bramley, A. J., Patel, A. H., O'Reilly, M., Foster, R. \& Foster, T. J. (1989). Roles of alpha-toxin and beta-toxin in virulence of Staphylococcus aureus for the mouse mammary gland. Infect Immun 57, 2489-2494.

Brouillette, E., Grondin, G., Shkreta, L., Lacasse, P. \& Talbot, B. G. (2003). In vivo and in vitro demonstration that Staphylococcus aureus is an intracellular pathogen in the presence or absence of fibronectinbinding proteins. Microb Pathog 35, 159-168.

Cabiscol, E., Tamarit, J. \& Ros, J. (2000). Oxidative stress in bacteria and protein damage by reactive oxygen species. Int Microbiol 3, 3-8.

Calvinho, L. F., Donnelly, W. J. \& Dodd, K. (1993). Effect of partially purified Staphylococcus aureus beta-haemolysin on the mammary gland of the mouse. Zentralbl Veterinarmed B 40, 559-568.

Cifrian, E., Guidry, A. J., Bramley, A. J., Norcross, N. L., BastidaCorcuera, F. D. \& Marquardt, W. W. (1996). Effect of staphylococcal $\beta$ toxin on the cytotoxicity, proliferation and adherence of Staphylococcus aureus to bovine mammary epithelial cells. Vet Microbiol 48, 187-198. 
Cosgrove, K., Coutts, G., Jonsson, I. M., Tarkowski, A., Kokai-Kun, J. F., Mond, J. J. \& Foster, S. J. (2007). Catalase (KatA) and alkyl hydroperoxide reductase (AhpC) have compensatory roles in peroxide stress resistance and are required for survival, persistence, and nasal colonization in Staphylococcus aureus. J Bacteriol 189, 1025-1035.

Cucarella, C., Tormo, M. A., Knecht, E., Amorena, B., Lasa, I., Foster, T. J. \& Penadés, J. R. (2002). Expression of the biofilm-associated protein interferes with host protein receptors of Staphylococcus aureus and alters the infective process. Infect Immun 70, 3180-3186.

Day, W. A., Jr, Sajecki, J. L., Pitts, T. M. \& Joens, L. A. (2000). Role of catalase in Campylobacter jejuni intracellular survival. Infect Immun 68, 6337-6345.

Dinges, M. M., Orwin, P. M. \& Schlievert, P. M. (2000). Exotoxins of Staphylococcus aureus. Clin Microbiol Rev 13, 16-34.

González-Zorn, B., Domínguez-Bernal, G., Suárez, M., Ripio, M. T., Vega, Y., Novella, S. \& Vázquez-Boland, J. A. (1999). The $s m c L$ gene of Listeria ivanovii encodes a sphingomyelinase $\mathrm{C}$ that mediates bacterial escape from the phagocytic vacuole. Mol Microbiol 33, 510-523.

Götz, F., Ahrne, S. \& Lindberg, M. (1981). Plasmid transfer and genetic recombination by protoplast fusion in staphylococci. J Bacteriol 145, 74-81.

Haima, P., van Sinderen, D., Schotting, H., Bron, S. \& Venema, G. (1990). Development of a $\beta$-galactosidase $\alpha$-complementation system for molecular cloning in Bacillus subtilis. Gene 86, 63-69.

Hannun, Y. A. \& Obeid, L. M. (1995). Ceramide: an intracellular signal for apoptosis. Trends Biochem Sci 20, 73-77.

Hébert, A., Sayasith, K., Sénéchal, S., Dubreuil, P. \& Lagacé, J. (2000). Demonstration of intracellular Staphylococcus aureus in bovine mastitis alveolar cells and macrophages isolated from naturally infected cow milk. FEMS Microbiol Lett 193, 57-62.

Horinouchi, S. \& Weisblum, B. (1982). Nucleotide sequence and functional map of pE194, a plasmid that specifies inducible resistance to macrolide, lincosamide, and streptogramin type B antibodies. J Bacteriol 150, 804-814.

Horsburgh, M. J., Clements, M. O., Crossley, H., Ingham, E. \& Foster, S. J. (2001). PerR controls oxidative stress resistance and iron storage proteins and is required for virulence in Staphylococcus aureus. Infect Immun 69, 3744-3754.

Huynh, H. T., Robitaille, G. \& Turner, J. D. (1991). Establishment of bovine mammary epithelial cells (MAC-T): an in vitro model for bovine lactation. Exp Cell Res 197, 191-199.

Kanafani, H. \& Martin, S. E. (1985). Catalase and superoxide dismutase activities in virulent and nonvirulent Staphylococcus aureus isolates. J Clin Microbiol 21, 607-610.

Kerro Dego, O., van Dijk, J. E. \& Nederbragt, H. (2002). Factors involved in the early pathogenesis of bovine Staphylococcus aureus mastitis with emphasis on bacterial adhesion and invasion. A review. Vet Q 24, 181-198.

Larsen, H. D., Aarestrup, F. M. \& Jensen, N. E. (2002). Geographical variation in the presence of genes encoding superantigenic exotoxins and $\beta$-hemolysin among Staphylococcus aureus isolated from bovine mastitis in Europe and USA. Vet Microbiol 85, 61-67.

Manca, C., Paul, S., Barry, C. E., III, Freedman, V. H. \& Kaplan, G. (1999). Mycobacterium tuberculosis catalase and peroxidase activities and resistance to oxidative killing in human monocytes in vitro. Infect Immun 67, 74-79.

Mandell, G. L. (1975). Catalase, superoxide dismutase, and virulence of Staphylococcus aureus. In vitro and in vivo studies with emphasis on staphylococcal-leukocyte interaction. J Clin Invest 55, 561-566.

Meier, B. (2001). Superoxide generation of phagocytes and nonphagocytic cells. Protoplasma 217, 117-124.
Menzies, B. E. \& Kourteva, I. (1998). Internalization of Staphylococcus aureus by endothelial cells induces apoptosis. Infect Immun 66, 5994-5998. Nilsson, I. M., Hartford, O., Foster, T. \& Tarkowski, A. (1999). Alphatoxin and gamma-toxin jointly promote Staphylococcus aureus virulence in murine septic arthritis. Infect Immun 67, 1045-1049.

O'Callaghan, R. J., Callegan, M. C., Moreau, J. M., Green, L. C., Foster, T. J., Hartford, O. M., Engel, L. S. \& Hill, J. M. (1997). Specific roles of alpha-toxin and beta-toxin during Staphylococcus aureus corneal infection. Infect Immun 65, 1571-1578.

Qazi, S. N., Counil, E., Morrissey, J., Rees, C. E., Cockayne, A., Winzer, K., Chan, W. C., Williams, P. \& Hill, P. J. (2001). agr expression precedes escape of internalized Staphylococcus aureus from the host endosome. Infect Immun 69, 7074-7082.

Ramos-Morales, F., Prieto, A. I., Beuzón, C. R., Holden, D. W. \& Casadesús, J. (2003). Role for Salmonella enterica enterobacterial common antigen in bile resistance and virulence. J Bacteriol 185, 5328-5332.

Reed, L. \& Muench, H. (1938). A simple method of estimating fifty per cent endpoints. Am J Hyg 27, 493-497.

Ripio, M. T., Geoffroy, C., Domínguez, G., Alouf, J. E. \& VázquezBoland, J. A. (1995). The sulphydryl-activated cytolysin and a sphingomyelinase $\mathrm{C}$ are the major membrane-damaging factors involved in cooperative (CAMP-like) haemolysis of Listeria spp. Res Microbiol 146, 303-313.

Sanz, R., Marín, I., Ruíz-Santa-Quiteria, J. A., Orden, J. A., Cid, D., Díez, R. M., Silhadi, K. S., Amils, R. \& de la Fuente, R. (2000). Catalase deficiency in Staphylococcus aureus subsp. anaerobius is associated with natural loss-of-function mutations within the structural gene. Microbiology 146, 465-475.

Seral, C., Van Bambeke, F. \& Tulkens, P. M. (2003). Quantitative analysis of gentamicin, azithromycin, telithromycin, ciprofloxacin, moxifloxacin, and oritavancin (LY333328) activities against intracellular Staphylococcus aureus in mouse J774 macrophages. Antimicrob Agents Chemother 47, 2283-2292.

Shompole, S., Henon, K. T., Liou, L. E., Dziewanowska, K., Bohach, G. A. \& Bayles, K. W. (2003). Biphasic intracellular expression of Staphylococcus aureus virulence factors and evidence for Agr-mediated diffusion sensing. Mol Microbiol 49, 919-927.

Sutra, L. \& Poutrel, B. (1994). Virulence factors involved in the pathogenesis of bovine intramammary infections due to Staphylococcus aureus. J Med Microbiol 40, 79-89.

Titball, R. W. (1993). Bacterial phospholipases C. Microbiol Rev 57, 347-366.

Vallejo, A. N., Pogulis, R. J. \& Pease, L. R. (1994). In vitro synthesis of novel genes: mutagenesis and recombination by PCR. PCR Methods Appl 4, S123-S130.

Vann, J. M. \& Proctor, R. A. (1988). Cytotoxic effects of ingested Staphylococcus aureus on bovine endothelial cells: role of $S$. aureus $\alpha-$ hemolysin. Microb Pathog 4, 443-453.

von Eiff, C., Heilmann, C., Proctor, R. A., Woltz, C., Peters, G. \& Gotz, F. (1997). A site-directed Staphylococcus aureus hemB mutant is a smallcolony variant which persists intracellularly. J Bacteriol 179, 4706-4712.

Ward, P. D., Adlam, C., McCartney, A. C., Arbuthnott, J. P. \& Thorley, C. M. (1979). A histopathological study of the effects of highly purified staphlococcal alpha and beta toxins on the lactating mammary gland and skin of the rabbit. J Comp Pathol 89, 169-177.

Wesson, C. A., Liou, L. E., Todd, K. M., Bohach, G. A., Trumble, W. R. \& Bayles, K. W. (1998). Staphylococcus aureus Agr and Sar global regulators influence internalization and induction of apoptosis. Infect Immun 66, 5238-5243.

Edited by: J. Lindsay 